\title{
Are the health Millennium Development Goals appropriate for Eastern Europe and Central Asia?
}

Bernd Rechel, Laidon Shapo and Martin McKee

with

The Health Nutrition and Population Group

Europe and Central Asia Region, The World Bank

11 November 2004 


\section{Acknowledgements}

This work was financed by the World Bank, from a trust fund provided by the Government of the Netherlands. However the findings, interpretations, and conclusions expressed here are those of the authors, and do not necessarily reflect the views of the Board of Executive Directors of the World Bank or the governments they represent. The authors worked with a counterpart team in the Health, Nutrition and Population Group of the Human Development Sector Unit, Europe and Central Asia Region of the World Bank, which included Olusoji Adeyi, Enis Baris, Sarbani Chakraborty, Armin Fidler, Dominic Haazen, Loraine Hawkins, Akiko Maeda, Daniel Miller, Michael Mills, Toomas Palu, Silviu Radulescu and Alan Wright. The authors are especially grateful to Olusoji Adeyi, who initiated and encouraged this work, and to Eduard Bos (of the Health, Nutrition and Population Central Unit in the World Bank) for information on mortality estimates and his comments on earlier versions of this report, to Marc Suhrcke of the World Health Organization (formerly of UNICEF) who provided valuable information on data quality, and to Karen Lock of the London School of Hygiene and Tropical Medicine, Vladimir Shkolnikov, of the Max Planck Institute for Demographic Research, and Evgueni Andreev, of the Russian Academy of Sciences, who contributed to the development of the methodology used here. 


\section{Summary}

This article argues that the health-related Millennium Development Goals do not appropriately address the challenges faced by the countries of Eastern Europe and Central Asia. By ignoring adult mortality, their achievement would result in relatively small gains in life expectancy. To achieve greater impact, policies in this region must supplement the classical Millennium Development Goals with indicators of adult health, in particular cardiovascular diseases and external causes of death. In addition, countries, with support from the international community, must improve the quality of vital registration data to enable more accurate estimation of the disease burden. 


\section{Introduction}

This paper examines the application of the health-related Millennium Development Goals (MDGs) to the countries of Eastern Europe and Central Asia. The MDGs originated from the United Nations Millennium Declaration in September 2000. They reflect key aims from various UN development conferences in the 1990s and build on the International Development Goals developed by the Organization for Economic Cooperation and Development (OECD) in 1996, including all but one of the OECD Goals (UNDP 2003). The MDGs are now widely accepted as a framework for measuring development progress and have become a central focus of development assistance of bilateral and multilateral institutions.

The overall aim of the MDGs is to reverse the spread of poverty and disease by 2015 . The eight goals are backed by a plan of action that sets out 18 quantifiable targets, each using specified indicators. Three goals and four targets are directly related to health. Goal 4 is to reduce child mortality. The related target is to reduce the under-five mortality rate by two-thirds, between 1990 and 2015. Goal 5 is the improvement of maternal health, with the target of reducing the maternal mortality rate by three-quarters, between 1990 and 2015. Goal 6 calls for combating HIV/AIDS, malaria and other diseases. The related targets are to have halted by 2015 and begun to reverse the spread of HIV/AIDS, and to have halted by 2015 and begun to reverse the incidence of malaria and other major diseases (The World Bank Group 2003; UNDP 2003).

Our analysis looks at the impact of four scenarios on life expectancy at birth:

1) achieving the targets set out in the MDGs for infant, child (1-4 years) and maternal mortality; 
2) reducing infant, child and maternal mortality to European Union levels (as an indicator of the situation in a part of Europe to which countries in this region often aspire);

3) reducing infant, child and maternal mortality to the lowest current levels in the sub-region (as an indication of what is arguably achievable now);

4) reducing deaths from cardiovascular disease and external causes of death to European Union levels (as an example of a strategy that would move on from the current MDGs to focus on major causes of adult mortality).

The MDGs focus the attention of the international community on important indicators of development (UNDP 2003; Haines and Cassels 2004). However, they are more relevant for some countries or regions than for others. We argue that the choice of MDGs and their corresponding targets focus on sub-Saharan Africa in two important ways. The major reason is that rates of under-five mortality, maternal mortality, and HIV/AIDS infection rates are the highest in the world and progress in reducing these rates have so far been very limited (UNDP 2003). The second reason is that, unlike other health problems, these are more easily visible. The 2000 World Health Report, for example, used childhood mortality to assess equity of outcome in its measure of health care system performance, because these data were much more widely available than data on adult mortality (WHO 2000). Data on infant, maternal, and to a lesser extent childhood mortality are collected in many developing countries either by means of routine collection systems or intermittent surveys, in particular the series of Demographic and Health Surveys. With the exception of some innovative sentinel programmes (Garenne, Kahn et al. 2000) and the recently established Indepth Network (www.indepth- 
network.org), much less systematic recording of adult mortality exists. As a consequence, estimated life expectancy at birth is derived by means of modeling techniques, in which available information is applied to standard life tables (Coale and Demeny 1966).

The choice of more readily available measures of childhood and maternal mortality as indicators of development is influenced by the view that they will broadly reflect the overall health of a population. Yet in those settings in the developing world where adult mortality has been studied it has also been found to be very high, especially from cardiovascular diseases and injuries (Garenne, Kahn et al. 2000; Walker, McLarty et al. 2000; Moshiro, Mswia et al. 2001). However this burden of avoidable disease remains largely invisible and has so far not been adequately used to monitor health trends.

In the former Soviet bloc the situation is different in both aspects. First of all, premature mortality is driven by deaths in adulthood. Childhood and maternal mortality, while still much higher than in advanced industrialized countries, have been reduced in the decades following the Second World War, although maternal mortality has increased again in many places after 1990. Furthermore, comprehensive systems to monitor vital statistics were put in place, which, although flawed, make it possible to measure and track adult mortality in a way that is not easily possible in sub-Saharan Africa.

Concerns have therefore been raised as to whether the health-related MDGs are appropriate for the transition countries of Eastern Europe and Central Asia, as they focus attention on childhood and maternal mortality and exclude general adult mortality. Our previous analysis of life expectancy in Russia argued that the health-related International Development Targets had limited relevance for Russia. The analysis covered the 
population of the Russian Federation in 1995-1999 and used life expectancy as the measure of population health. A reduction of infant and child mortality rates by twothirds and maternal mortality rates by three-quarters was found to result in an overall increase of only 0.96 years in life expectancy at birth. In contrast, a 20\% reduction in adult mortality would have resulted in an increase of 1.86 years in male life expectancy. A further analysis looked at the effect of narrowing the east-west gap in Europe; a reduction of adult mortality to British levels for cardiovascular diseases and external causes of death resulted in an increase in life expectancy at birth of 5.97 years for both sexes (Lock, Andreev et al. 2002).

Apart from this analysis on Russia, surprisingly little has been published on the appropriateness of global development targets for health in Eastern Europe and Central Asia. Our search using PubMed/Medline in June 2003 could not identify any other publication on the subject. Nevertheless, the situation is likely to be similar in many other Eastern European transition countries. In these countries, under-five and maternal mortality are much lower than in countries at similar levels of economic development in other parts of the world. Adult mortality, on the other hand, contributes most to the burden of disease and premature mortality. Deaths due to cardiovascular diseases exceed the European Union average in all countries of Eastern Europe and Central Asia, reaching levels of 807 per 100,000 population in the Russian Federation in 2001, as compared to a European Union level of 258 per 100,000 in 1999, with higher levels among males than among females (WHO/Europe 2003). Deaths due to external causes (injuries, poisoning, homicide and suicide) are also much higher than in the European Union prior to enlargement in 2004 (EU-15), in particular among men and in some countries of the 
former Soviet Union. In the Russian Federation in 2001, deaths due to external causes numbered 224 per 100,000, compared to a EU-15 level of 40 per 100,000 in 1999 (WHO/Europe 2003). The rates of homicide and intentional injury among males in 1999 were 32 times higher in the Russian Federation than in the EU-15 (WHO/Europe 2003). Some other elements of the MDGs may be more applicable to Eastern Europe and Central Asia. The rapid spread of HIV/AIDS and the re-emergence of tuberculosis are two major threats to health in this region, particularly in the countries of the former Soviet Union. This highlights the relevance of Millennium Development Goal 6, concerned with the spread of HIV/AIDS, malaria and other diseases (including tuberculosis). However, the impact on mortality and thus life expectancy at birth of these diseases is still relatively low when compared with non-communicable diseases and external causes of death, although this may change in the near future. Given the large and increasing number of HIV infections and the very limited availability of antiretroviral treatment, it is clear that the HIV epidemic in Eastern Europe and Central Asia, in particular in Russia and Ukraine, may have a devastating impact on mortality patterns in the near future, especially when combined with the growth in tuberculosis. A recent World Bank study predicted an increase in the cumulative number of HIV-infected individuals in Russia in an "optimistic scenario" from 1.2 million in 2005 to 2.3 million in 2010 and 5.4 million in 2020. Mortality rates would increase from 500 per month in 2005 to 21,000 per month in 2020 (Rühl, Pokrovsky et al. 2002). On the basis of the 2001 life table, this increase in mortality would result in a decrease in life expectancy in the Russian Federation by 3.19 years, reaching 62.16 years. A second major challenge will be to halt the spread of tuberculosis in the former Soviet Union. The reported 
incidence of tuberculosis in the Russian Federation in 2002 was 90 per 100,000 population, and the Baltic states and the Russian Federation have some of the highest documented rates of multidrug-resistant tuberculosis anywhere in the world. Efforts have been undertaken to halt the spread of communicable diseases, but much more remains to be done (Rechel and McKee 2004).

Before proceeding with the scenarios considered in this article, the following Section 2 discusses the quality of the data used. Section 3 then describes the methods applied in the analytical part of the study. Section 4 provides the results of the analysis, which are discussed in more detail in Section 5. Finally, Section 6 draws conclusions that are relevant to the region and the focus of development assistance. 


\section{Data Quality}

Although the government of the Soviet Union and its eastern European satellites created extensive systems of vital registration, it cannot be assumed that health data for Eastern Europe and Central Asia are now of uniformly high quality. A major problem in some countries is the absence of accurate population data. Since 1989, wars and conflicts, combined with economic and social turmoil and the opening of borders, have triggered large-scale population movements that have often remained poorly quantified.

Another problem is that health information systems deteriorated or, in some cases, collapsed. A recalculation of life expectancy in Georgia concluded that official data may overestimate life expectancy at birth by as much as 8 years (Badurashvili, McKee et al. 2001).

Shifting definitions is a further problem. A study in Croatia showed that official mortality data were unreliable for the 1990 s, with one of the main problems that the population denominator used before 1996 included not only people living in Croatia, but also Croatian citizens living permanently abroad (Bozicevic, Oreskovic et al. 2001).

Particularly serious concerns have been raised about the quality of data on infant and child mortality, in particular for Central Asia and the Caucasus. This can be illustrated by the case of Tajikistan where the reported rate of child mortality in 1999 is 1.16 compared to an EU-15 level of 1.02 per 1,000 live births in the same year, while the figure given for 1990 was 20.56. It is apparent that, given the sequelae of civil war in Tajikistan and the breakdown in many governmental functions, including presumably vital registration, the recent data on child mortality must be treated with considerable skepticism. 
More detailed studies in these countries have identified three main factors that may contribute to the underestimation of childhood mortality (UNICEF 2001; McKee, Healy et al. 2002; Aleshina and Redmond 2003; Government of Tajikistan 2003; UNICEF 2003). The first is that in many countries of Central Asia and the Caucasus, the Soviet definition of live birth is still in use. This reclassifies many very premature babies as stillbirths, with the effect of reducing the infant mortality rate by $22-25 \%$ (Aleshina and Redmond 2003). Armenia, Georgia and Kyrgyzstan have recently adopted the WHO definition of a live birth, but in practice implementation has been only partial. In the remaining countries of Central Asia and the Caucasus, the Soviet definition is still in use (Aleshina and Redmond 2003). The second factor contributing to official underestimates is the misreporting of births and infant deaths by medical staff. The third factor contributing is that births and deaths of children are not reported by parents to the authorities, due to fees for registration. In Kazakhstan, Kyrgyzstan and Tajikistan, fees for registration have been abolished in the last two years, but in Georgia there are still fees for the registration of births. Where mothers are not in a registered marriage, the charge is doubled, resulting in an increased risk of under-registration of children of single mothers (Aleshina and Redmond 2003).

In view of these problems with the quality of data, UN organizations such as UNICEF and the World Bank have produced alternative data sets on infant and child mortality, using models that include data from surveys and other sources. As a consequence, the health-related Millennium Development targets that were established on the basis of estimates of 1990 levels, as well as measurement of progress towards these targets by 
World Bank and UNDP are based on World Bank estimates of infant and child mortality rather than on national registration data.

Although estimates based on survey data are likely to reflect the real infant mortality rates in Central Asia and the Caucasus better than national registration data, they too have limitations. Surveys are associated with a number of errors that limit their capacity to gauge current levels of infant and child mortality and even more so when assessing infant and child mortality up to ten years previously. Where indirect estimates of infant mortality are used, as in the Multiple Indicator Cluster Surveys, extra potential sources of error are introduced (Aleshina and Redmond 2003).

The methods used to estimate childhood mortality from these data have been neither consistent nor transparent. In effect, different UN organizations are using different datasets and it is often unclear, or at least very difficult to discover, what data were used and how the resulting figures were generated. Interpretation and subjective judgments play a considerable part in production of the estimates. The uncertainties associated with surveys and survey-based estimates mean that surveys can only ever be partial solutions to the problem of incomplete vital registration.

A more fundamental drawback when using World Bank data is that some indicators, such as maternal mortality rates in 1990, are missing from the published tables and others, such as infant mortality, are incomplete. If the intention is to track changes, WHO, recording national registration data supplied by the countries, is the only complete source of the data required. However, since the quality of data in many countries is either poor or doubtful, the data have limited usefulness for serious policy decisions. 
As long as national registration is incomplete, the exact levels of childhood mortality in Central Asia and the Caucasus will remain unknown. In this context, the analysis of the impact of the health-related Millennium Development Goals on these countries in the current study was confronted with the choice of whether to use national registration data or survey-based estimates. It was decided to use both datasets in two parallel calculations. National registration data were used for all scenarios considered in this study. Where, in addition, survey-based estimates by the World Bank were available for the countries of Central Asia and the Caucasus, as was the case for infant and child mortality, an additional analysis based on these estimates was undertaken. Although neither of these two approaches may be entirely accurate, the aim was to make the best use of currently available data. 


\section{Methods}

This analysis is primarily based on population and mortality data by age, sex and cause of death, as reported by national statistical offices to the WHO in June 2003. The latest updates by WHO at this time were from 10 February 2003 for the population data and from 31 December 2002 for the mortality data. Using these data, life tables were calculated based on standard methods (Chiang 1968), as was done in the earlier study of the Russian Federation (Lock, Andreev et al. 2002). The analysis covered all countries of the World Bank's Europe and Central Asia region (here designated as "Eastern Europe and Central Asia"), with the exceptions of Bosnia and Herzegovina, Serbia and Montenegro and Turkey, for which no recent population or mortality data were available. Using the official data reported by the countries to WHO, life expectancies were tabulated. The effects on life expectancy at birth were then calculated for the following four scenarios:

1) achieving MDG targets for infant, child and maternal mortality;

2) reducing infant, child and maternal mortality to EU-15 levels;

3) reducing infant, child and maternal mortality to the lowest sub-regional levels;

4) keeping infant, child and maternal mortality constant and reducing deaths from cardiovascular disease and external causes of death to EU-15 levels.

Where regional and sub-regional averages are shown they have been populationweighted. In countries that have already achieved or over-achieved the target levels of the scenarios, the lower of the two figures was taken as the target, as it was assumed, for present purposes, that none of these countries (all among the most advanced in the 
region) would relinquish their achievements. As maternal mortality ratios are expressed in terms of numbers of live births it was necessary to adapt them for use in the life tables. This was done by setting the target as the current death rate from maternal causes in the age group 15-49 times the ratio of the target maternal mortality rate per 100,000 live births to the current rate. In effect this meant assuming that the current live birth rate would be unchanged.

As has been noted previously, achievement of Millennium Development Goal 6 (combating HIV/AIDS, malaria, and tuberculosis) has not been included in the analysis, since the impact of these diseases on life expectancy at birth is still relatively small. However, it is important to recognize that this will change dramatically in the near future. Scenario 1 explored the impact on life expectancy at birth of reaching the MDGs for infant, child and maternal mortality. The MDGs consider progress from a designated baseline, the year 1990. Infant, child, and maternal mortality rates for 1990 were taken from the January 2003 version of the WHO HFA database to establish the MDG targets for 2015. The most recent available data for infant, child, and maternal mortality from the WHO HFA database were used to analyze the effects on life expectancy, if these indicators could be reduced to MDG levels.

In Scenario 2, life tables were recalculated on the basis of achieving the most recent EU15 levels for infant, child and maternal mortality, showing the effects on life expectancy. In Scenario 3, infant, child and maternal mortality of each country were reduced to the lowest levels achieved within four sub-regional groupings:

1) Former communist EU candidate countries (status of 2003); 
2) South Eastern Europe excluding EU candidates Bulgaria and Romania (Albania, Croatia and Macedonia);

3) Central Asia and Caucasus;

4) The remaining countries of the former Soviet Union (Belarus, Moldova, Russia, Ukraine).

Scenario 4 kept infant, child and maternal mortality rates constant, and reduced the deaths from cardiovascular disease and external causes of deaths to the current EU-15 average.

Because of the known problems with data from Central Asia and the Caucasus, the analyses for these countries were undertaken separately in the first three scenarios for infant and child mortality, using both national vital registration data as reported to WHO and World Bank estimates of infant and child mortality. In the latter case, World Bank estimates of infant and child mortality rates were substituted in the life tables. For Scenario 1, the targets for Goal 4 were established on the basis of World Bank estimates of infant and mortality rates for 1990. For Scenario 3, the lowest sub-regional rates of infant and child mortality were similarly established on the basis of World Bank estimates. 


\section{$4 \quad$ Results}

As the first step of the analysis, life expectancies were tabulated for the countries of Eastern Europe and Central Asia, using national registration data supplied to the WHO. In the case of Central Asia and the Caucasus, this analysis was complemented by an adjustment of life tables with World Bank estimates on infant and child mortality. Because these estimates show much higher values than the official data reported to the WHO, life expectancies in all countries of this region would be considerably lower if the World Bank's estimates of infant and child mortality rates are assumed to be more accurate. Figure 1 shows the results of recalculations of life tables according to different estimates of infant and child mortality. The difference is most dramatic for Tajikistan, where life expectancy would be reduced by 13.4 years.

\section{Figure 1}

Using the calculated life expectancies, the impact of the different scenarios on life expectancy was then analyzed. For the countries of Central Asia and the Caucasus, two complimentary analyses were undertaken, the first based on national registration data, the second based on World Bank estimates of infant and child mortality rates.

The results of the four scenarios are summarized in Table 1 and 2 and Figure 2. In the whole of Eastern Europe and Central Asia, as well as in all four sub-regions and in most individual countries, the gain in life expectancy was by far greatest in Scenario 4. Reducing mortality levels from cardiovascular disease and external causes of death to EU-15 levels would result in an average gain of 7.75 years. 
The reductions in infant, child and maternal mortality in Scenarios 1-3, on the other hand, would result in markedly lower gains in life expectancy. Scenario 1 (reaching the MDGs for infant, child and maternal mortality) resulted in an average ECA gain of between 0.68 and 1.24 years. Scenario 2 (reaching EU-15 levels for infant, child and maternal mortality) would result in an average gain of 0.85-1.57 years, while Scenario 3 (reaching the lowest sub-regional levels of infant, child and maternal mortality) would result in an average gain of 0.58-1.09 years.

In Central Asia and the Caucasus, gains in the first three scenarios were considerably higher, when the calculations were based on World Bank estimates of infant and child mortality. In this case, average sub-regional gains would be 4.04 years in Scenario 1, 5.60 years in Scenario 2 and 4.02 years in Scenario 3. At a country level, Tajikistan would gain most (12.29 years) in Scenario 2.

Several countries of the former Soviet Union stand to make considerable gains under Scenario 4 (based on national registration data). These countries are the Russian Federation (10.09 years), Turkmenistan (9.70 years), Ukraine (8.67 years), Kazakhstan (8.63 years), Lithuania (7.47 years) and Latvia (7.20 years).

\section{Table 1}

Table 2

Figure 2 


\section{Discussion}

\subsection{Implications for systems of data collection}

One of the major issues this study faced was the scale of the problems with existing data on which to judge progress towards identified targets in many countries. As noted above, there is currently no consensus on the true scale of infant and child mortality rates in Central Asia and the Caucasus. Estimates differ not only between national governments and international organizations, but between UN organizations themselves. This ultimately threatens the credibility of the estimates. International agencies should publish the basis on which they have derived their estimates for key health indicators and should initiate a process to achieve consensus on the best estimates for each country.

It is especially important to involve national governments in this dialogue, thus securing national ownership of estimates generated by international organizations and strengthening the case for improvements in national vital registration. It is essential that the governments of Central Asia and the Caucasus recognize that life expectancies are likely to be dramatically lower than official data suggest.

Governments and international agencies should place a high priority on strengthening systems for vital registration. As a first step it will be necessary to address the main factors that contribute to the discrepancies between official and survey data in Central Asia and the Caucasus. First, it is important that all countries adopt and implement fully the WHO definition of a live birth rather than the Soviet one. Second, training for health care staff is required to reduce misreporting of infant deaths. This will need to be accompanied by the abolition of incentives that lead staff to underreport infant mortality, 
such as the systems of control and sanctions that inhibit open discussion of adverse events. It will also require the creation of suitable incentives to increase the accuracy of reporting. Third, to ensure the reporting of births and deaths by parents, registration fees should be abolished where they still exist, as in Georgia. There are also many examples of how registration can be linked to access to benefits (financial and otherwise) to create positive incentives to improve vital registration. However it should also be recognized that some countries in Central Asia or the Caucasus may be reluctant to improve the accuracy of their data, as high official infant mortality rates would portray their countries in a negative light.

While national registration is still incomplete, it is possible to improve the quality of survey data. One way is by increasing the sample sizes, consequently narrowing confidence intervals and providing more accurate estimates, as well as by increasing the number of surveys, taking into account the problem of selective non-response of interviewees. This is most acute in the countries of Central Asia and the Caucasus, but also concerns other countries in Eastern Europe and Central Asia, where concerns about the quality of data have been raised, but where hardly any surveys have been undertaken so far.

\subsection{Policy choices and combination of indicators}

Obviously, health targets and policy interventions need to be adapted to the individual country context. Perhaps the most important message of this study is that simply following global development targets will not be the best way to enhance the health of the populations in Eastern Europe and Central Asia. The reason for this is that the burden 
of disease and mortality varies widely between countries and generally differs markedly from the patterns observed in developing countries.

The eight countries of Central Asia and the Caucasus exhibit very high under-5 and maternal mortality rates. It is those countries that would benefit most from achieving the MDGs as this will lead to a substantial improvement in overall health. In those countries where infant, under-5 and maternal mortality remain high there is a continuing need to direct resources to policies that will reduce them. This is likely to include strengthening basic social services and primary health care although, given the need to reflect local context, it will also be important not simply to transfer uncritically policies from other parts of the world. Instead, international agencies, bilateral donors and global foundations should support primary research into the causes of adverse health outcomes among these populations.

In addition to high rates of childhood mortality, some of the countries of Central Asia and the Caucasus are at the same time struggling with staggering rates of adult mortality. One of the main findings that emerged from this study is that the health-related MDGs need to be adapted to Eastern Europe and Central Asia, so that they include adult mortality. This is particularly true of the countries of the former Soviet Union, but also of other countries of Eastern Europe and Central Asia. A potential average gain of 7.75 years in life expectancy at birth, when reducing mortality from cardiovascular diseases and external causes of death to EU-15 levels, simply cannot be ignored.

There are various ways in which adult mortality could be included in the MDGs. One way of doing so would be to include additional health indicators under Target 8 of Goal 6. At the most general level, life expectancy at birth could be used as an additional 
indicator. More specifically, major causes of adult mortality could be used as indicators of development. Although there are problems with the accuracy of mortality data in some countries of the region, these inaccuracies are unlikely to be any greater than those for traditional MDG indicators, and may even be less. Two additional indicators important for Eastern Europe and Central Asia are those used in this study, namely mortality rates from cardiovascular disease and external causes of death.

\subsection{Need for development assistance}

It is not necessary to wait for mortality levels to change to assess progress. Instead, it is possible to intervene to address the main risk factors for cardiovascular disease, tracking changes that will appear before mortality declines. Cardiovascular disease arises as a consequence of a complex set of risk factors, including tobacco use, physical inactivity and unhealthy diet and although the precise contribution of different factors in this region differs from that in western populations (for example, the very low levels of dietary antioxidants and the consequences of episodic heavy drinking), changes in the prevalence of key risk factors could be used as additional indicators under Target 8 of Millennium Development Goal 6. So far, however, available data on the prevalence of relevant risk factors is very limited. Again, the gathering of more accurate data would help to direct policy responses to where they are most needed.

Appropriate policy interventions to reduce the high levels of adult mortality must include the strengthening of public health services, with more emphasis on health promotion and disease prevention. Concerted public health efforts are in particular required to counteract the tobacco epidemic which is spreading in Eastern Europe and Central Asia. The spread of tuberculosis, including multidrug-resistant tuberculosis, and HIV/AIDS are 
other strong reminders of the need for such improvements in public health programs, including health promotion activities. The high rates of external causes of death, in particular among infants and children, call for concerted efforts to prevent injuries, especially during childhood.

In general, international assistance should be focused on the countries in Eastern Europe and Central Asia with the largest burden of disease and premature mortality. As this study has shown, this concerns not only infant, child and maternal mortality, but also adult mortality. In this sense, the current study highlights where the need for development assistance in the health sector is greatest. The allocation of resources to the countries with the highest burden of mortality and disease could also be an incentive to improve vital registration systems. 


\section{Conclusion}

A policy aimed at reducing mortality levels from cardiovascular disease and external causes of death to the levels in the EU-15 emerges as having the greatest potential to impact on life expectancy at birth, outweighing potential gains that might be achieved when reducing infant and child mortality. In summary, it can therefore be concluded that this study has made the case for complementing the MDGs in Eastern Europe and Central Asia with another set of goals or indicators that take into account adult mortality, while at the same time showing the benefits of reducing infant and child mortality in Central Asia and the Caucasus. In order to judge progress towards identified targets, governments and international agencies need to place a high priority on strengthening systems for vital registration, in particular in the countries of Central Asia and the Caucasus.

As already noted, Millennium Development Goal 6 could be used to complement the traditional MDGs, focusing on reversing the spread of HIV/AIDS and reducing the incidence of malaria and "other major diseases". Yet, the only other disease specified in the related indicators in addition to HIV/AIDS and malaria is tuberculosis. Nevertheless, the use of the term "other major diseases" in the Goal makes it possible to include other major diseases that are more relevant in a specific country or regional context. This might leave countries room within the framework of the MDGs to identify and tackle the diseases that cause the most damage to their populations, offering an opportunity for dialogue between governments and international agencies to operationalize appropriate targets. In Eastern Europe and Central Asia, these targets should include cardiovascular diseases and external causes of death, including the prevention of accidents, suicides and homicides. Both cardiovascular diseases and external causes of death are much more 
prevalent among males than among females and policies addressing their causes need to take account of this gender dimension.

This study highlights the great variety among the countries of Eastern Europe and Central Asia. As the potential gains in life expectancy indicate, levels of infant, child and maternal mortality, as well as of mortality from cardiovascular diseases and external causes, vary widely among the different countries of the region. At one extreme is Slovenia, which would achieve almost no gain in life expectancy in the first three scenarios and only 1.36 years in Scenario 4. At the other end are Tajikistan, gaining 12.29 years in Scenario 2, and Turkmenistan, gaining 9.70 years in Scenario 4. Obviously, these countries need to adopt different strategies to improve the health of their populations. This illustrates that appropriate policy interventions need to be developed at a country level and should not slavishly follow global development goals. It would clearly be mistaken to establish common goals for all countries of Eastern Europe and Central Asia.

Going beyond Eastern Europe and Central Asia, the study allows two more general conclusions. The first concerns adult mortality. The importance of non-communicable diseases and external causes of death is more obvious in the countries of Eastern Europe and Central Asia because vital registration systems, while imperfect, are much better than in other countries at comparable levels of development. However their importance is not confined to this region. It is often forgotten that non-communicable diseases and injuries account for more than half of all lost years of healthy life in developing countries (UNDP 2003). Mortality from these causes of death could be used as additional indicators of progress towards the MDGs, where data are available. This view has now been endorsed 
by senior WHO experts, calling for the inclusion of adult mortality and morbidity in the MDGs (Kowal and Lopez 2003).

The second conclusion concerns life expectancy. Life expectancy is not only the most general summary measure of mortality in a population, but also a measure of social development. An increase in life expectancy should therefore be a global development goal in itself. Improvements in life expectancy have previously been used as UN development goals. A UN General Assembly resolution in 1980 called for raising life expectancy in all countries to 60 years by 2000 . In 124 of the 173 countries that fell below that level this goal has been achieved (UNDP 2003).

As was noted previously, this study has been limited to the analysis of the potential impact of reaching MDGs 4 and 5. Although mortality from HIV/AIDS is still comparatively low, this is likely to change in the near future. Studies modeling the future impact of HIV in this region exist but they are limited by the lack of contextually valid data on, for example, exposure to risk in the countries involved. International agencies should continue their efforts to develop models of the future impact of HIV and tuberculosis in the region, paying particular attention to the complexities of the coexistence of HIV and multi-drug resistant tuberculosis, exploring various scenarios and policy responses, and linking this information to Goal 6 so as to contribute to the discussion of the appropriateness of the MDGs to Eastern Europe and Central Asia. 


\section{References}

Aleshina, N. and G. Redmond (2003). How High is Infant Mortality in Central and Eastern Europe and the CIS?, Innocenti Working Paper No.99. Florence, Innocenti Research Centre.

Badurashvili, I., M. McKee, et al. (2001). "Where there are no data: what has happened to life expectancy in Georgia since 1990?" Public Health 115: 394-400.

Bozicevic, I., S. Oreskovic, et al. (2001). "What is happening to the health of the Croatian population?" Croatian Medical Journal 42(6): 601-5.

Chiang, C. L. (1968). Introduction to stochastic processes in biostatistics. New York, John Wiley \& Sons, Inc.

Coale, A. and P. Demeny (1966). Regional Model Life Tables and Stable Populations. Princeton NJ, Princeton Univ. Press.

Garenne, M., K. Kahn, et al. (2000). "Causes of death in a rural area of South Africa: an international perspective." J Trop Pediatr 46: 183-90.

Government of Tajikistan (2003). Progress toward the Millennium Development Goals in the Republic of Tajikistan, Draft, 30 April 2003. Dushanbe, Government of Tajikistan.

Haines, A. and A. Cassels (2004). "Can the millennium development goals be attained?" British Medical Journal 329(7462): 394-397.

Kowal, P. R. and A. D. Lopez (2003). "Child survival." The Lancet 362: 915.

Lock, K., E. M. Andreev, et al. (2002). "What targets for international development policies are appropriate for improving health in Russia." Health Policy and Planning 17(3): 257-263. 
McKee, M., J. Healy, et al., Eds. (2002). Health care in central Asia. European Observatory on Health Care Systems Series.

Moshiro, C., R. Mswia, et al. (2001). "The importance of injury as a cause of death in sub-Saharan Africa: results of a community-based study in Tanzania." Public Health 115: 96-102.

Rechel, B. and M. McKee (2004). Learning lessons from the experience of the Task Force on Communicable Disease Control in the Baltic Sea Region. Programme evaluation. London, London School of Hygiene \& Tropical Medicine.

Rühl, C., V. Pokrovsky, et al. (2002). The Economic Consequences of HIV in Russia (www.worldbank.org.ru). Washington, World Bank.

The World Bank Group (2003). Millennium Development Goals - website (http://www.developmentgoals.org/index.html, accessed on 12 March 2004).

UNDP (2003). Human Development Report 2003. New York, Oxford, Oxford University Press.

UNICEF (2001). A Decade of Transition. Florence, Innocenti Research Centre.

UNICEF (2003). Social Monitor 2003. Florence, UNICEF Innocenti Research Centre.

Walker, R., D. McLarty, et al. (2000). "Stroke mortality in urban and rural Tanzania. Adult Morbidity and Mortality Project." Lancet 355: 1684-7.

WHO (2000). The World Health Report 2000. Health Systems: improving performance. Genveva, World Health Organization. WHO/Europe (2003). "HFA Database, January 2003." 


\section{Appendix: The Millennium Development Goals}

Goal 1: Eradicate extreme poverty and hunger

Goal 2: Achieve Universal Primary Education

Goal 3: Promote Gender Equality and Empower Women

Goal $4 *$ : Reduce child mortality

Target 5: Reduce by two-thirds, between 1990 and 2015, the under-five mortality rate

Indicators: Under-five mortality rate

Infant mortality rate

Proportion of one-year-old children immunized against measles

\section{Goal 5*: Improve maternal health}

Target 6: Reduce by three-quarters, between 1990 and 2015, the maternal mortality rate

Indicators: Maternal mortality ratio

Proportion of births attended by skilled health personnel

Goal 6*: Combat HIV/AIDS, malaria and other diseases

Target 7: Have halted by 2015 and begun to reverse the spread of HIV/AIDS

Indicators: HIV prevalence among 15- to 24-year-old pregnant women

Contraceptive prevalence rate

Number of children orphaned by HIV/AIDS

Target 8: Have halted by 2015 and begun to reverse the incidence of malaria and other major diseases

Indicators: Prevalence and death rates associated with malaria

Proportion of population in malaria-risk areas using effective malaria prevention and treatment measures

Prevalence and death rates associated with tuberculosis

Proportion of tuberculosis cases detected and cured under DOTS

\section{Goal 7: Ensure environmental sustainability}

Goal 8: Build a global partnership for development

Source: World Bank Group. http://www.developmentgoals.org/About the goals.htm. Accessed on March 12, 2004.

*: Examined in this study. 
Figure 1 Life Expectancies in Central Asia and the Caucasus according to different estimates of infant and child mortality

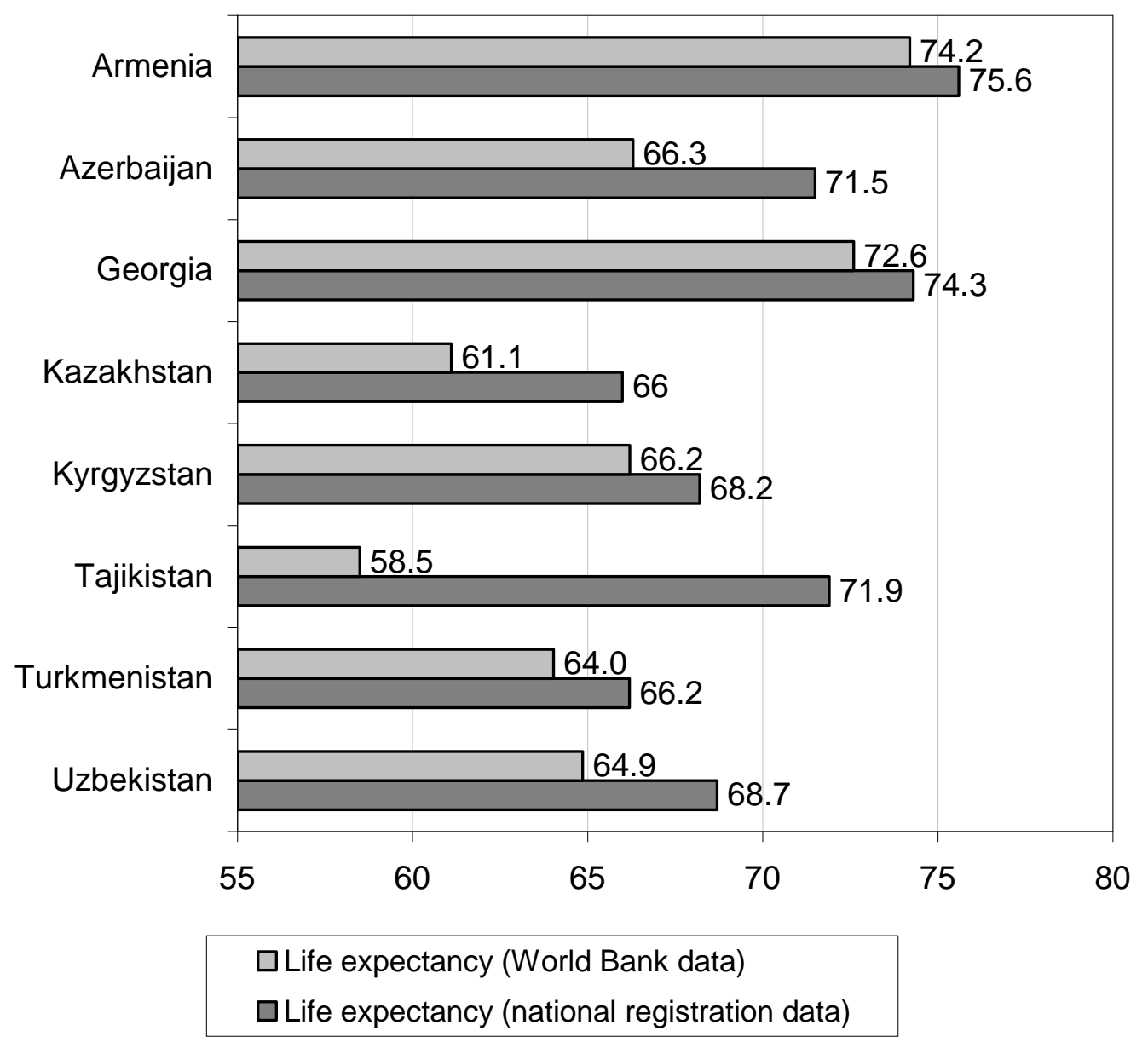

Note: Data refer to latest available years 


\section{Figure 2 Gain in Life Expectancy According to the Different Scenarios:}

\section{Regional and Sub-regional averages}

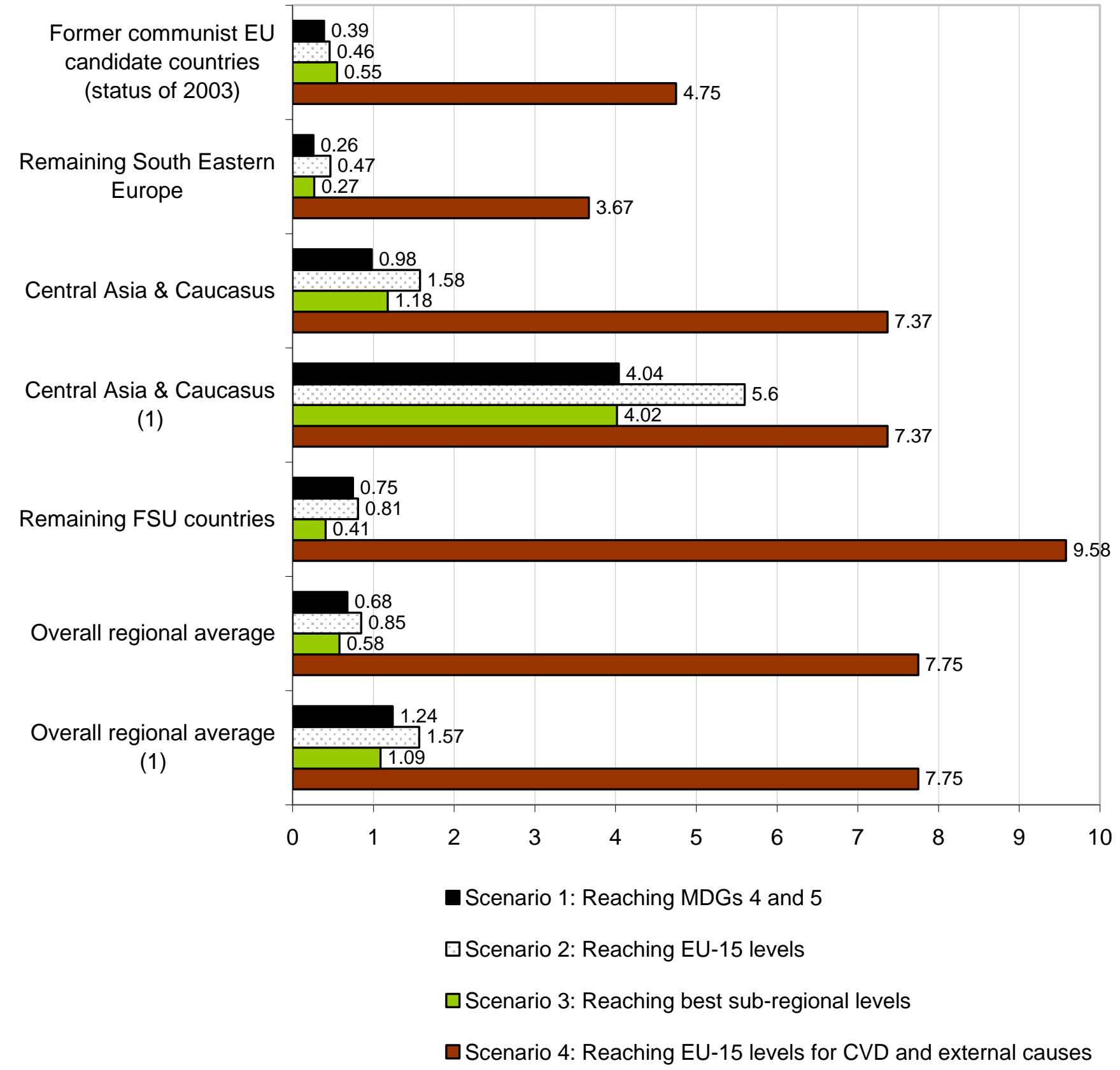

Note: (1) based on World Bank data on infant and child mortality in Central Asia and Caucasus 


\section{Table 1 Gain in Life Expectancy According to the Different Scenarios}

\begin{tabular}{|c|c|c|c|c|}
\hline & $\begin{array}{c}\text { Scenario 1: } \\
\text { Reaching } \\
\text { MDGs } 4 \text { and } 5\end{array}$ & $\begin{array}{c}\text { Scenario 2: } \\
\text { Reaching EU-15 } \\
\text { levels }\end{array}$ & $\begin{array}{c}\text { Scenario 3: } \\
\text { Reaching best } \\
\text { sub-regional } \\
\text { levels }\end{array}$ & $\begin{array}{c}\text { Scenario 4: } \\
\text { Reaching EU-15 } \\
\text { levels for CVD } \\
\text { and external } \\
\text { causes }\end{array}$ \\
\hline \multicolumn{5}{|c|}{ Former communist EU candidate countries (status of 2003) } \\
\hline Bulgaria & 0.76 & 0.77 & 0.88 & 6.57 \\
\hline Czech Republic & 0.07 & 0 & 0.05 & 3.50 \\
\hline Estonia & 0.39 & 0.37 & 0.48 & 6.72 \\
\hline Hungary & 0.27 & 0.26 & 0.36 & 4.29 \\
\hline Latvia & 0.49 & 0.48 & 0.09 & 7.20 \\
\hline Lithuania & 0.45 & 0.34 & 0.45 & 7.47 \\
\hline Poland & 0.24 & 0.25 & 0.36 & 3.30 \\
\hline Romania & 0.73 & 1.12 & 1.22 & 6.85 \\
\hline Slovakia & 0.40 & 0.31 & 0.42 & 4.65 \\
\hline Slovenia & 0.12 & 0 & 0.02 & 1.36 \\
\hline Sub-regional average & 0.39 & 0.46 & 0.55 & 4.75 \\
\hline \multicolumn{5}{|l|}{ South Eastern Europe } \\
\hline Albania & 0.20 & 0.76 & 0.55 & 3.10 \\
\hline Croatia & 0.31 & 0.19 & 0 & 3.54 \\
\hline Macedonia & 0.24 & 0.65 & 0.40 & 4.84 \\
\hline Sub-regional average & 0.26 & 0.47 & 0.27 & 3.67 \\
\hline \multicolumn{5}{|c|}{ Remaining countries of the former Soviet Union } \\
\hline Belarus & 0.48 & 0.42 & 0 & 7.52 \\
\hline Moldova & 0.90 & 1.07 & 0.64 & 7.36 \\
\hline Russian Federation & 0.79 & 0.88 & 0.48 & 10.09 \\
\hline Ukraine & 0.67 & 0.65 & 0.26 & 8.67 \\
\hline Sub-regional average & 0.75 & 0.81 & 0.41 & 9.58 \\
\hline Overall ECA average & 0.68 & 0.85 & 0.58 & 7.75 \\
\hline Overall ECA average (1) & 1.24 & 1.57 & 1.09 & \\
\hline
\end{tabular}

Note: (1) based on World Bank data on infant and child mortality in Central Asia and Caucasus; data refer to latest available years; no recent data available for Bosnia and Herzegovina, Serbia and Montenegro and Turkey 
Table 2 Gain in Life Expectancy According to the Different Scenarios (Central Asia and Caucasus)

\begin{tabular}{|c|c|c|c|c|c|c|c|}
\hline & \multicolumn{4}{|c|}{ National registration data } & \multicolumn{3}{|c|}{ World Bank data } \\
\hline & $\begin{array}{c}\text { Scenario 1: } \\
\text { Reaching MDGs } 4 \\
\text { and } 5\end{array}$ & $\begin{array}{c}\text { Scenario 2: } \\
\text { Reaching EU- } \\
15 \text { levels }\end{array}$ & $\begin{array}{c}\text { Scenario 3: } \\
\text { Reaching best } \\
\text { sub-regional } \\
\text { levels }\end{array}$ & $\begin{array}{c}\text { Scenario 4: } \\
\text { Reaching EU- } \\
15 \text { levels for } \\
\text { CVD and } \\
\text { external causes }\end{array}$ & $\begin{array}{l}\text { Scenario 1: } \\
\text { Reaching } \\
\text { MDGs } 4 \text { and } 5\end{array}$ & $\begin{array}{c}\text { Scenario 2: } \\
\text { Reaching EU- } \\
15 \text { levels }\end{array}$ & $\begin{array}{c}\text { Scenario 3: } \\
\text { Reaching best } \\
\text { sub-regional } \\
\text { levels }\end{array}$ \\
\hline Armenia & 0.86 & 1.02 & 0.58 & 4.36 & 1.38 & 2.38 & 0.72 \\
\hline Azerbaijan & 0.73 & 1.31 & 0.89 & 6.47 & 3.98 & 5.71 & 4.48 \\
\hline Georgia & 0.57 & 0.63 & 0.03 & 6.39 & 1.92 & 2.29 & 0.07 \\
\hline Kazakhstan & 1.02 & 1.39 & 1.01 & 8.63 & 5.05 & 5.74 & 4.41 \\
\hline Kyrgyzstan & 1.44 & 1.99 & 1.59 & 5.67 & 2.41 & 3.82 & 2.35 \\
\hline Tajikistan & 0.48 & 0.82 & 0.68 & 5.19 & 7.97 & 12.29 & 10.55 \\
\hline Turkmenistan & 2.05 & 3.05 & 2.69 & 9.70 & 3.37 & 5 & 3.67 \\
\hline Uzbekistan & 0.97 & 1.89 & 1.43 & 7.98 & 3.72 & 5.39 & 3.62 \\
\hline Sub-regional average & 0.98 & 1.58 & 1.18 & 7.37 & 4.04 & 5.60 & 4.02 \\
\hline
\end{tabular}

Note: Data refer to latest available years 